\title{
Evaluasi Kegagalan Cacat Korosi Internal Pipa Minyak Sepinggan Dengan Metode Element Hingga
}

\author{
H. Lesmana* dan I. Kusumaningtyas \\ Departemen Teknik Mesin dan Industri, Fakultas Teknik, Universitas Gadjah Mada. \\ Jl. Grafika No.2, Kompleks UGM, Yogyakarta 55281, Indonesia, \\ Telp. (0274) 521673 \\ e-mail: hery.lesmana@mail.ugm.ac.id
}

\begin{abstract}
Abstrak
Pipa Sepinggan sudah terkena serangan korosi internal dan perlu dievaluasi agar dapat dioperasikan dengan aman. Evaluasi dengan ASME-B31G level 1 sangat konservatif sehingga bisa jadi kondisi pipa dinilai terlalu rendah dan akhirnya dilakukan perbaikan berbiaya mahal yang tidak perlu. Disamping itu, evaluasi dengan cara ini juga tidak memperhitungkan besar kecilnya lebar korosi. Untuk itu, diperlukan penelitian dengan FEM untuk mengetahui konservatisme penggunaan ASME B31G level 1, termasuk pada variasi lebar korosi, sehingga hasil evaluasi cacat korosi nya dan keputusan apakah pipa ini perlu diperbaiki dapat dihasilkan dengan akurat. Penelitian ini diawali dengan studi literatur, kemudian dilanjutkan dengan pemodelan cacat korosi pada pipa dengan bantuan program Ansys Workbench yang divalidasi dengan data referensi. Model yang tervalidasi kemudian digunakan untuk simulasi efek lebar korosi pada tekanan pecah pipa. Dari hasil simulasi FEM diketahui konservatisme dari ASMEB31G Level 1 dan faktor koreksi yang harus diberikan agar perhitungannya akurat. Selanjutnya pipa Sepinggan dievaluasi dengan metode yang memberikan akurasi tertinggi. Dari hasil penelitian, konservatisme ASME-B31G level 1 memerlukan beberapa faktor koreksi terkait dengan lebar korosinya.
\end{abstract}

Kata kunci : Pengaruh lebar korosi, korosi internal, tekanan pecah pipa.

\begin{abstract}
The Sepinggan pipe has been exposed to internal corrosion and needs to be evaluated for safe operation. Evaluation with ASME-B31G level 1 can be very conservative, the pipeline may be considered too bad and finally requiring needless expensive repairs. This evaluation also does not consider corrosion width. For this reason, research with FEM is needed to find out the conservatism of using ASME-B31G level 1, including variations in corrosion width, so that the results of the evaluation of corrosion defects and the decision whether these pipes need to be repaired can be produced accurately. This research begun with literature study, followed by pipe corrosion defect modeling in Ansys Workbench and validated using reference data. Validated model then used for simulation of corrosion width effect on pipe burst pressure. Based on the simulation, the conservatism and correction factor to increase accuracy for the usage of ASME-B31G Level 1 was found. Finally, Sepinggan pipe was evaluated using the method that bring the most accurate result. This study found, ASME-B31G level 1 conservatism require correction factors related to its corrosion width.
\end{abstract}

Keywords : Corrosion width effect, internal corrosion, pipe burst pressure. 


\section{PENDAHULUAN}

Pipa Sepinggan sudah terkena serangan korosi internal dan perlu dievaluasi agar dapat dioperasikan dengan aman. Evaluasi dengan ASME-B31G level 1 sangat konservatif sehingga bisa jadi kondisi pipa dinilai terlalu rendah dan akhirnya dilakukan perbaikan berbiaya mahal yang tidak perlu. Disamping itu, evaluasi dengan cara ini juga tidak memperhitungkan besar kecilnya lebar korosi.

Karena cacat korosi aktual memiliki geometri yang lebih kompleks, seperti contohnya memiliki lebar, untuk akurasi evaluasi cacat korosi sehingga dapat menghindarkan dari perbaikan pipa yang tidak perlu yang berbiaya mahal, diperlukan penelitian untuk mengetahui pengaruh variasi lebar korosi terhadap persentase akurasi penggunaan analisa level 1 ASME-B31G dalam menghitung tekanan pecah pipa pada pipa API 5L X52 Sepinggan ini atau mencari tahu apakah ada faktor koreksi terhadap penggunaan perhitungan dengan ASME-B31G level 1 untuk mendapatkan hasil evaluasi mendekati tekanan pecah sebenarnya. Selanjutnya metode evaluasi terbaik diterapkan untuk mengevaluasi pengaruh korosi internal pada pipa Sepinggan secara akurat.

Banyak model analisa cacat korosi pada pipa dikembangkan hanya berdasarkan pertimbangan area memanjang arah longitudinal dari daerah cacat. Geometri dari cacat korosi bisa dilihat pada Gambar 1 dibawah ini.

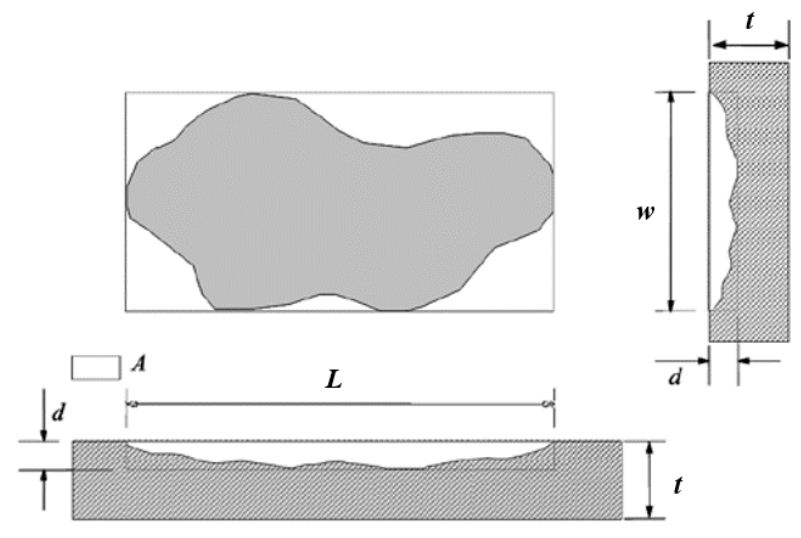

Gambar 1. Geometri cacat korosi

Pendekatan untuk memproyeksikan area logam yang hilang akibat korosi pada arah bidang longitudinal pipa seperti yang diproyeksikan A pada gambar 1 dapat bervariasi dari pendekatan bentuk persegi panjang $(d x L)$, pendekatan bentuk parabola $(2 / 3 d x L)$, campuran $45 \%$ bentuk persegi panjang dan $55 \%$ bentuk parabola $(0,85 \mathrm{dxL})$ sampai pendekatan ke area "sebenarnya" dengan metode element hingga.

Dengan $\sigma_{\mathrm{hf}}$ adalah tegangan melingkar saat pipa mengalami kegagalan (MPa, psi), $\sigma_{\text {flow }}$ adalah tegangan alir (MPa, psi), $\mathrm{A}_{\circ}$ adalah area longitudinal yang utuh sebelum terjadi korosi yang merupakan fungsi dari ketebalan awal pipa (t) dan panjang cacat $(\mathrm{L})\left(A_{o}=t x L\right)\left(\mathrm{mm}^{2}\right.$, in $\left.^{2}\right), A_{c}$ adalah area yang terkorosi, yang merupakan fungsi dari kedalaman (d) dan panjang cacat (L) $\left(\mathrm{mm}^{2}\right.$, in $\left.^{2}\right), M$ adalah Folias atau faktor gembung, $L$ adalah panjang korosi $(\mathrm{mm}$, in), $d$ adalah kedalaman korosi ( $\mathrm{mm}$, in) dan $t$ adalah tebal pipa ( $\mathrm{mm}$, in), pendekatan yang paling konservatif dengan bentuk persegi panjang $(A=d x L)$, digunakan oleh model NG-18 berikut ini: 


$$
\sigma_{\text {hf }}=\sigma_{\text {flow }}\left[\frac{1-\left({ }^{A_{c}} / A_{o}\right)}{1-\left({ }^{A_{c}} / A_{o}\right) M^{-1}}\right]
$$

Dengan $P_{b}$ adalah tekanan pecah (MPa, psi), $\sigma_{\text {flow }}=1,1 \sigma_{y s}$ adalah tegangan alir (MPa, psi), $\sigma_{y s}$ adalah kekuatan luluh material (MPa, psi), $D$ adalah diameter pipa (mm, in), model ASME B31G menggunakan bentuk parabola $(2 / 3 d x L)$, dengan persamaan sebagai berikut:

Untuk cacat yang pendek $\left(\mathrm{L}^{2} / \mathrm{Dt}<=20\right)$

$$
P_{b}=\frac{2 t}{D} \sigma_{\text {flow }}\left[\frac{1-\frac{2}{3}\left(\frac{d}{t}\right)}{1-\frac{2}{3}\left(\frac{d}{t M}\right)}\right] \text { dengan } \quad M=\sqrt{1+0,8\left(\frac{L}{D t}\right)^{2}}
$$

Untuk cacat panjang $\left(\mathrm{L}^{2} / \mathrm{Dt}>20\right)$

$$
P_{b}=\frac{2 t}{D} \sigma_{\text {flow }}\left[1-\left(\frac{d}{t}\right)\right]
$$

Selanjutnya, model B31G yang dimodifikasi menggunakan bentuk $(0,85 d x L)$, yang berada di antara bentuk persegi panjang dan parabola.

Semua model penilaian analitikal diatas, membuat perkiraan dari area cacat berdasarkan pada kedalaman dan panjang maksimum L. Namun, parameter untuk efek lebar korosi belum termasuk dalam metode penilaian, untuk menentukan tekanan pecah pipa yang mengandung cacat permukaan.

Beberapa analisis dan percobaan telah dilakukan untuk menentukan kekuatan pipa yang tersisa dampak dari cacat korosi. Namun kebanyakan teknik penilaian dan penelitian yang tersedia dilaporkan dalam literatur telah mengabaikan kemungkinan efek lebar lubang korosi.

Alang dkk. meneliti efek cacat korosi pada tekanan pecah melalui pengujian eksperimental dan numerik. Namun demikian penelitian ini mengabaikan lebar cacat korosi dalam perhitungan tekanan pecah. Penelitian ini juga menghasilkan kesimpulan bahwa hasil FEM selalu memprediksi nilai tekanan pecah yang lebih tinggi dibandingkan dengan ASME B31G dan Modifikasi ASME B31G, dimana ASME B31G adalah kode desain yang memberikan hasil yang paling konservatif.

Sedikit penelitian yang menganalisa dampak lebar korosi pada kegagalan pipa dengan menggunakan FEM. Salah satu penelitian yang dilakukan oleh Orasheva dengan membuat lebar korosi yang diasumsikan terkait dengan panjang (L) dan/atau kedalaman korosi (d) dari percobaan pipa sampai pecah yang sudah ada. Menurut penelitian Orasheva tersebut, hasil ini menunjukkan bahwa ada perbedaan antara hasil eksperimen dengan hasil FEM ketika lebar lubang korosi divariasikan. Hasil penelitian Orasheva ini cukup penting, walaupun pengaruh lebar korosi belum dikuantifikasi terhadap kode ASME-B31G dan tidak dijelaskan keterkaitannya dengan panjang korosi yang pendek atau panjang, namun sudah menunjukkan bahwa lebar korosi mempengaruhi tekanan pecah hasil analisa dengan FEM.

Penelitian lainnya yang memasukkan parameter lebar korosi terhadap perhitungan tekanan pecah pada pipa adalah yang dilakukan Mustaffa dan van Gelder untuk cacat korosi yang dangkal $(\mathrm{d} / \mathrm{t} \leq 0,3)$, pendek $(\mathrm{L} / \mathrm{D} \leq 0,20)$, dan lebar $(\mathrm{w} / \mathrm{t}>0,5)$, dengan $\sigma_{u}$ adalah tegangan tarik maksimum dan $w$ adalah lebar korosi, didapati bahwa tekanan pecah pipa tersebut tergantung kepada besarnya lebar cacat (w) dengan persamaan sebagai berikut:

$$
\frac{P_{b}}{\sigma_{u}}=\left(\frac{t}{D}\right)^{0,8442}\left(\frac{d}{t}\right)^{-0,0545}\left(\frac{L}{w}\right)^{-0,014}
$$

Dalam studi FEM, kriteria kegagalan diperlukan untuk menentukan kapan fraktur terjadi. Banyak penelitian tekanan pecah pipa dengan FEM telah menggunakan kriteria kegagalan 
berbasis tegangan von Mises yang dibandingkan dengan kekuatan tarik maksimum bahan dalam studi mereka, dengan hasil yang akurat terlepas dari ketebalan dinding pipa. Salah satunya adalah yang sudah dilakukan oleh Orasheva untuk material API 5L X52 yang sama dengan penelitian ini dan telah dilaporkan menghasilkan hasil yang akurat.

Tujuan penelitian ini yang pertama adalah untuk mengetahui pengaruh variasi lebar korosi terhadap persentase akurasi penggunaan analisa level 1 ASME-B31G dalam menghitung tekanan pecah pipa. Yang kedua adalah menentukan faktor koreksi terhadap penggunaan perhitungan dengan ASME-B31G level 1 apabila memperhitungkan lebar korosi.

\section{METODE PENELITIAN}

Penelitian ini diawali dengan studi literatur, kemudian dilanjutkan dengan pemodelan cacat korosi pada pipa dengan bantuan program Ansys Workbench 16.0.

\subsection{Data Material}

Data material yang digunakan untuk membuat model FEM pada penelitian ini diambil dari data pengujian tekanan pecah sebenarnya yang tercatat pada laporan PRCI no: L51689. Data material yang diambil adalah data untuk material API 5L X52 yang memiliki besar diameter dan ketebalan pipa yang sama seperti pada Tabel 1:

Tabel 1. Data material untuk penelitian

\begin{tabular}{|l|c|l|l|c|c|c|c|c|}
\hline Kasus & $\begin{array}{c}\mathrm{D} \\
(\mathrm{mm})\end{array}$ & $\begin{array}{c}\mathrm{t} \\
(\mathrm{mm})\end{array}$ & $\begin{array}{c}\mathrm{d} \\
(\mathrm{mm})\end{array}$ & $\begin{array}{c}\mathrm{L} \\
(\mathrm{mm})\end{array}$ & $\begin{array}{c}\mathrm{w} \\
(\mathrm{mm})\end{array}$ & $\begin{array}{c}\mathrm{S}_{\mathrm{Y}} \\
(\mathrm{MPa})\end{array}$ & $\begin{array}{c}\mathrm{S}_{\mathrm{UT}} \\
(\mathrm{MPa})\end{array}$ & $\begin{array}{c}\mathrm{P}_{\text {f-EXP }} \\
(\mathrm{MPa})\end{array}$ \\
\hline 27 & 762,00 & 9,53 & 3,71 & 139,70 & 149,00 & 414,1 & 555,47 & 12,68 \\
\hline 28 & 762,00 & 9,53 & 2,92 & 114,30 & 87,50 & 418,90 & 563,94 & 13,06 \\
\hline 29 & 762,00 & 9,53 & 5,84 & 101,60 & 79,00 & 446,50 & 612,65 & 12,23 \\
\hline 30 & 762,00 & 9,53 & 5,31 & 40,60 & 30,50 & 476,80 & 666,12 & 14,75 \\
\hline 31 & 762,00 & 9,53 & 5,31 & 50,80 & 50,00 & 449,20 & 617,41 & 13,78 \\
\hline 81 & 762,00 & 9,53 & 6,22 & 685,80 & 295,00 & 473,80 & 660,82 & 6,84 \\
\hline
\end{tabular}

Pipa dianggap gagal dan mengalami pecah pada saat tegangan Von Mises nya akibat tekanan tertentu menyamai kekuatan tarik maksimum dari material. Data kekuatan tarik maksimum pada tabel 1 di atas diekstrapolasi dari kekuatan luluh vs kekuatan tarik maksimum untuk material API 5L X52 PSL 2 yang standar.

Penelitian pengujian tekanan pecah menggunakan perangkat lunak FEM dilakukan dengan metode nonlinear. Dari kurva tegangan - regangan pipa API 5L standar [10], diperoleh pendekatan bahwa regangan pada saat tegangan material menyentuh kekuatan luluh adalah 0,002 $\mathrm{mm} / \mathrm{mm}$ dan regangan pada saat tegangan material menyentuh kekuatan maksimum adalah 0,15 $\mathrm{mm} / \mathrm{mm}$. Dengan data ini dapat digambarkan kurva bilinear pada perangkat lunak FEM untuk simulasi kasus nonlinear pipa pecah.

\subsection{Jenis Korosi Pada Pipa}

Dari hasil inspeksi yang dilakukan pada pipa penyalur minyak di Sepinggan ini, pipa tersebut sudah terkena pitting corrosion pada permukaan dalamnya, dengan ukuran geometri cacat korosi yang bervariasi. Terdapat juga beberapa cacat korosi yang berdekatan pada satu lokasi dan 
membentuk area korosi yang lebih luas. Pada penelitian ini cacat korosi diasumsikan hanya menyebabkan penipisan ketebalan pipa pada area cacat korosi.

\subsection{Pemodelan FEM}

Untuk mendapatkan model pipa yang memiliki cacat korosi secara akurat, pada penelitian ini dibuat 3 model cacat korosi, yaitu model kotak persegi, model dengan fillet dan model elips untuk melihat mana dari model tersebut yang tekanan pecahnya paling mendekati dengan tekanan pecah pada data referensi, seperti pada Gambar 2:

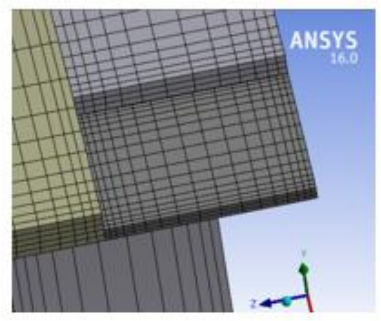

(1) Kotak

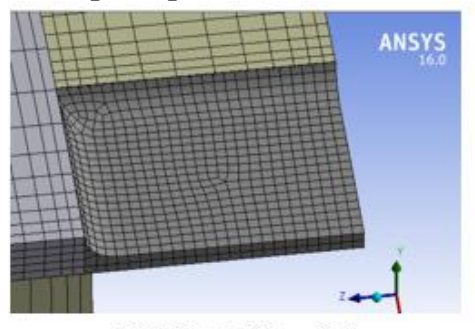

(2) Fillet ditiap sisi

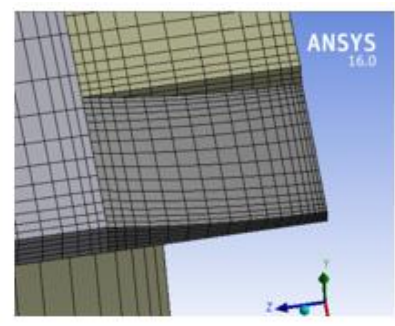

(3) Ellips

Gambar 2. Model cacat korosi

\subsection{Validasi Model FEM}

Untuk validasi, model FEM dibuat sehingga didapatkan model FEM yang perbandingan tekanan pecah aktual dari data referensi dan prediksi di model FEM menunjukkan kecocokan yang baik (+/- 10\%). Persentase 10\% ini diambil karena mechanical property dari material yang dijadikan referensi pada pembuatan model FEM ini merupakan hasil pendekatan seperti diterangkan pada bagian material diatas.

\subsection{Simulasi Penyelesaian Masalah}

Model yang tervalidasi kemudian digunakan untuk simulasi efek lebar korosi pada tekanan pecah pipa. Variasi lebar korosi (w) dibuat bervariasi dari 10\% panjang korosi (L) sampai maksimum selebar 350 deg keliling pipa. Untuk panjang korosi sendiri diambil dua contoh, dimana satu contoh merepresentasikan kondisi cacat yang pendek $\left(\mathrm{L}^{2} / \mathrm{Dt}<=20\right)$ dan satu contoh lainnya untuk cacat yang panjang ( $\left.\mathrm{L}^{2} / \mathrm{Dt}>20\right)$, sesuai dengan kondisi batas persamaan yang digunakan pada ASME B31G level 1. Dari hasil simulasi FEM diketahui perbandingan dan konservatisme dari ASME-B31G Level 1 dan faktor koreksi yang harus diberikan agar perhitungannya $<=10 \%$ dari hasil evaluasi FEM pada lebar korosi terkait. Selanjutnya pipa Sepinggan dievaluasi dengan metode yang memberikan akurasi tertinggi.

\section{HASIL DAN PEMBAHASAN}

\subsection{Validasi Dan Pemilihan Model FEM}

Gambar 3 adalah hasil simulasi pipa dengan cacat eksternal untuk ketiga model pada semua kasus pada data penelitian. Pada Gambar 3 tersebut dapat dilihat bahwa seluruh model, baik model dengan bentuk cacat korosi model kotak persegi, dengan fillet dan dengan elips memberikan ketepatan tekanan pecah pipa di atas 90\% dibandingkan dengan hasil pengujian pada data referensi sehingga seluruh model tervalidasi. Namun demikian, untuk penelitian ini, dipilih model dengan model bentuk elips yang memiliki ketepatan paling tinggi (di atas 94-95\%), untuk mendapatkan hasil penelitian yang lebih baik. 


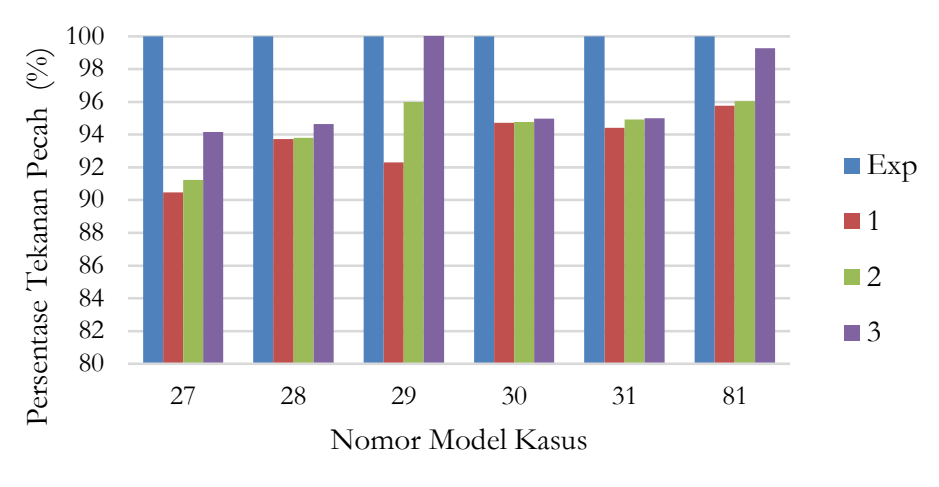

Gambar 3. Persentase tekanan pecah $\left(\mathrm{P}_{\mathrm{B}}\right)$ dikorelasikan dengan tekanan pecah $\left(\mathrm{P}_{\mathrm{B}}\right)$ hasil pengujian, untuk kasus Exp, Model 1, 2 Dan 3

Dari hasil simulasi, tidak terdapat perbedaan tekanan pecah antara hasil simulasi model pipa dengan cacat eksternal dibandingkan dengan cacat internal, sehingga model ini valid untuk diaplikasikan pada penelitian evaluasi kegagalan akibat cacat korosi internal.

\subsection{Pengaruh Lebar Korosi Pada Tekanan Pecah}

Data untuk pemodelan dan simulasi pengaruh lebar korosi pada tekanan pecah pada penelitian ini diambil dari data korosi internal sebenarnya hasil inspeksi pipa Sepinggan. Pada laporan inspeksi tersebut, terdapat 4 kasus yang paling kritis korosinya dan digunakan pada penelitian ini. Pada Tabel 2 dapat ditemukan 4 kasus tersebut, berikut data korosi dan data materialnya.

Tabel 2. Data korosi pipa Sepinggan

\begin{tabular}{|l|c|l|l|l|l|l|l|l|}
\hline Kasus & $\begin{array}{c}\mathrm{D} \\
(\mathrm{mm})\end{array}$ & $\begin{array}{c}\mathrm{t} \\
(\mathrm{mm})\end{array}$ & $\begin{array}{c}\mathrm{d} \\
(\mathrm{mm})\end{array}$ & $\begin{array}{c}\mathrm{L} \\
(\mathrm{mm})\end{array}$ & $\begin{array}{c}\mathrm{w} \\
(\mathrm{mm})\end{array}$ & $\begin{array}{c}\mathrm{S}_{\mathrm{Y}} \\
(\mathrm{MPa})\end{array}$ & $\mathrm{L}^{2} / \mathrm{Dt}$ & $\begin{array}{c}\mathrm{S}_{\mathrm{UT}} \\
(\mathrm{MPa})\end{array}$ \\
\hline 1 & 323,85 & 9,53 & 6,00 & 32,00 & 37,00 & 358,53 & 0,4 & 455,05 \\
\hline 2 & 323,85 & 9,53 & 5,81 & 34,00 & 33,00 & 358,53 & 0,4 & 455,05 \\
\hline 3 & 323,85 & 9,53 & 6,00 & 30,00 & 30,00 & 358,53 & 0,3 & 455,05 \\
\hline 4 & 323,85 & 9,53 & 5,72 & 32,00 & 61,00 & 358,53 & 0,4 & 455,05 \\
\hline $5^{*}$ & 323,85 & 9,53 & 5,81 & 300,00 & 33,00 & 358,53 & 31,0 & 455,05 \\
\hline $6^{*}$ & 323,85 & 9,53 & 2,00 & 34,00 & 33,00 & 358,53 & 0,4 & 455,05 \\
\hline
\end{tabular}

Untuk kasus $\mathrm{L}^{2} / \mathrm{Dt}<=20$, dipilih dari kasus 2 pada Tabel 2 di atas, dimana nilai $\mathrm{L}^{2} / \mathrm{Dt}=0,4$. Karena 4 kasus korosi pipa Sepinggan pada Tabel 2 di atas memiliki L2/Dt $<=20$, kemudian dibuat satu kasus yang diberi nama kasus $5^{*}$ dengan data yang sama dengan kasus 2 , namun dengan panjang korosi $\mathrm{L}$ yang berbeda sehingga nilai $\mathrm{L}^{2} / \mathrm{Dt}>20$. Lalu dibuat satu kasus lainnya diberi nama $6^{*}$ yang memiliki data yang sama dengan kasus 2 , namun dengan kedalaman korosi yang berbeda agar nilai $\mathrm{d} / \mathrm{t}<=0,3$. Kasus-kasus tambahan ini ditambahkan pada Tabel 2 di atas.

Untuk kasus 2, dimana nilai $\mathrm{L}^{2} / \mathrm{Dt}=0,4\left(\mathrm{~L}^{2} / \mathrm{Dt}<=20\right)$, hasil simulasi pengaruh variasi lebar korosi terhadap tekanan pecah pipa terlihat pada Gambar 4. 
Pada Gambar 4 tersebut dapat dilihat bahwa pada seluruh variasi lebar korosi, perhitungan dengan ASME B31G Level 1 memberikan hasil di bawah hasil simulasi FEM. Hasil perhitungan tekanan pecah dengan ASME B31G Level 1 adalah 13-20\% lebih rendah jika dibandingkan dengan hasil simulasi FEM. Pada Gambar 4 tersebut juga dapat dilihat bahwa lebar korosi mempengaruhi tekanan pecah pada pipa. Semakin lebar korosinya, semakin kecil tekanan pecah pada pipa.

Agar tekanan pecah yang dihitung menggunakan ASME-B31G dapat mendekati tekanan pecah sebenarnya dengan perbedaan kurang dari 10\%, untuk panjang korosi yang pendek dimana $\mathrm{L}^{2} / \mathrm{Dt}<=20$, dengan pendekatan regresi linear pada Gambar 4, penggunaan analisa level 1 ASME-B31G perlu ditambahkan faktor koreksi akibat lebar korosi (w) pada tekanan pecahnya sehingga persamaannya menjadi:

Untuk w $<20 \operatorname{deg}$

$$
P_{b}=1,13\left\{\frac{2 t}{D} \sigma_{\text {flow }}\left[\frac{1-\frac{2}{3}\left(\frac{d}{t}\right)}{1-\frac{2}{3}\left(\frac{d}{t M}\right)}\right]\right\}-0,026\left[\frac{(20-w) d e g}{1 \text { deg }}\right]
$$

Untuk $20 \operatorname{deg}=<\mathrm{w}<90 \operatorname{deg}$

$$
P_{b}=1,13\left\{\frac{2 t}{D} \sigma_{\text {flow }}\left[\frac{1-\frac{2}{3}\left(\frac{d}{t}\right)}{1-\frac{2}{3}\left(\frac{d}{t M}\right)}\right]\right\}-0,007\left[\frac{(w-20) \text { deg }}{1 \text { deg }}\right]
$$

Untuk $\mathrm{w}=>90 \mathrm{deg}$

$$
P_{b}=1,11\left\{\frac{2 t}{D} \sigma_{\text {flow }}\left[\frac{1-\frac{2}{3}\left(\frac{d}{t}\right)}{1-\frac{2}{3}\left(\frac{d}{t M}\right)}\right]\right\}-0,003\left[\frac{(w-90) \mathrm{deg}}{1 \mathrm{deg}}\right]
$$

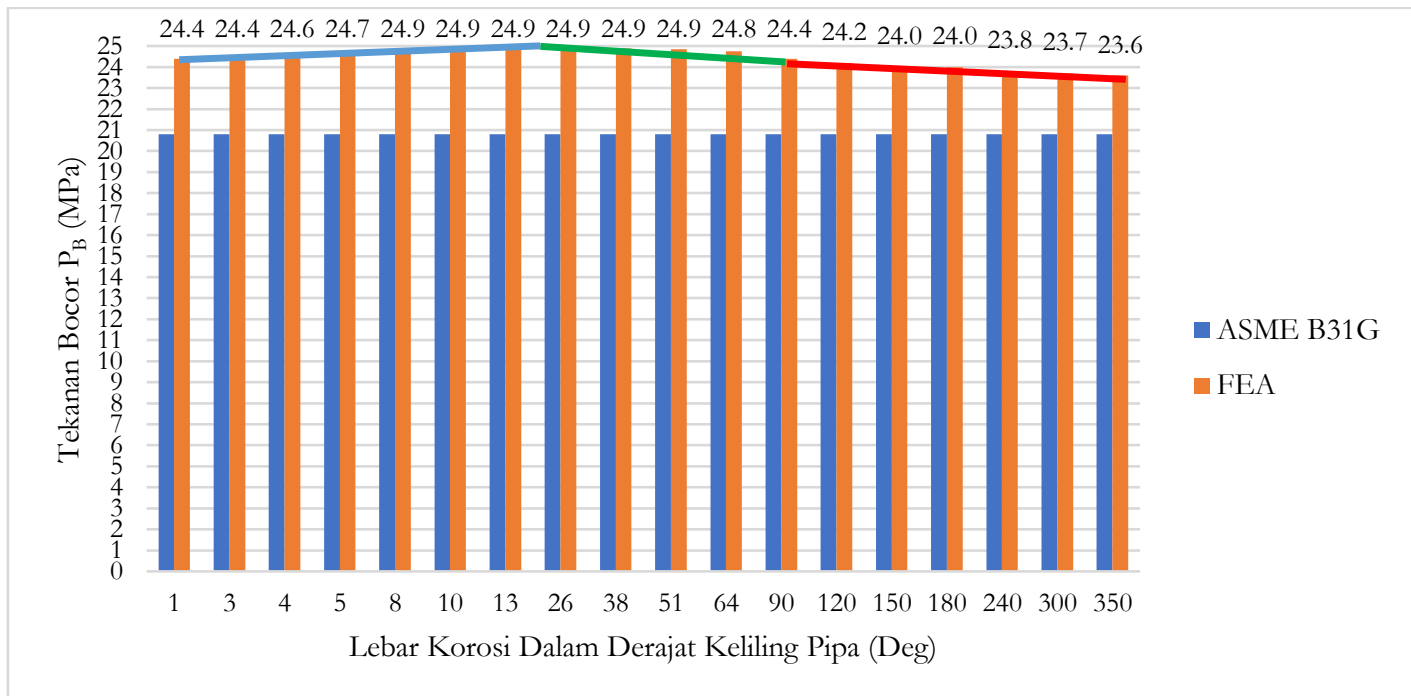

Gambar 4. Efek variasi lebar korosi pada tekanan pecah $\left(\mathrm{P}_{\mathrm{B}}\right)$ untuk kasus 2

Pada Gambar 4 juga terlihat, pada lebar korosi yang sempit atau sangat kecil, tekanan pecah pada pipa juga terlihat turun. Menurut peneliti, hal ini dikarenakan adanya konsentrasi tegangan 
pada celah sempit yang terbentuk akibat korosi sehingga mempengaruhi tegangan yang terjadi pada area tersebut. Hal ini dapat diteliti lebih lanjut pada penelitian lainnya.

Untuk kasus 5*, dimana nilai $\mathrm{L}^{2} / \mathrm{Dt}=31\left(\mathrm{~L}^{2} / \mathrm{Dt}>20\right)$, hasil simulasi pengaruh variasi lebar korosi terhadap tekanan pecah pipa terlihat pada Gambar 5.

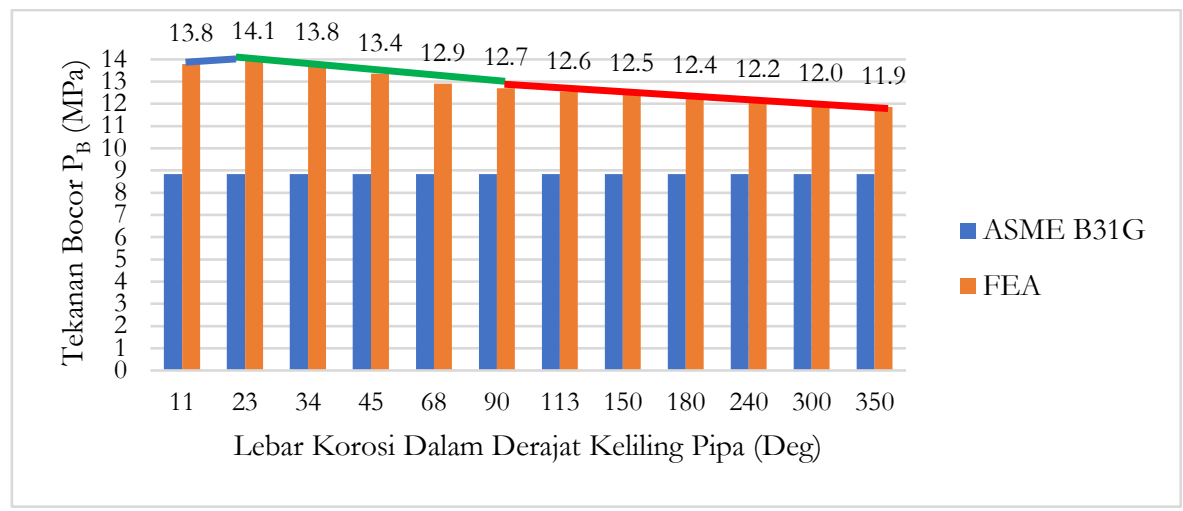

Gambar 5. Efek variasi lebar korosi pada tekanan pecah $\left(\mathrm{P}_{\mathrm{B}}\right)$ untuk kasus $5^{*}$

Pada Gambar 5 tersebut dapat dilihat bahwa untuk kasus $5^{*}$ dengan L2/Dt>20, pada seluruh variasi lebar korosi, perhitungan dengan ASME B31G Level 1 memberikan hasil yang lebih jauh di bawah hasil simulasi FEM. Hasil perhitungan tekanan pecah dengan ASME B31G Level 1 untuk kasus 5* dengan $\mathrm{L}^{2} / \mathrm{Dt}>20$ ini adalah 34-60\% lebih rendah jika dibandingkan dengan hasil simulasi FEM. Pada Gambar 5 tersebut juga dapat dilihat bahwa variasi lebar korosi pada panjang korosi yang panjang, lebih mempengaruhi tekanan pecah pada pipa. Semakin lebar korosinya, semakin kecil tekanan pecah pada pipa.

Agar tekanan pecah yang dihitung menggunakan ASME-B31G dapat mendekati tekanan pecah sebenarnya, dengan pendekatan regresi linear pada Gambar 5, untuk panjang korosi yang panjang dimana $\mathrm{L}^{2} / \mathrm{Dt}>20$, penggunaan analisa level 1 ASME-B31G perlu ditambahkan faktor koreksi akibat lebar korosi $(\mathrm{w})$ pada tekanan pecahnya sehingga persamaannya menjadi:

Untuk $\mathrm{w}<20 \operatorname{deg}$

$P_{b}=1,52\left\{\frac{2 t}{D} \sigma_{\text {flow }}\left[\frac{1-\frac{2}{3}\left(\frac{d}{t}\right)}{1-\frac{2}{3}\left(\frac{d}{t M}\right)}\right]\right\}-0,033\left[\frac{(20-w) \text { deg }}{1 \text { deg }}\right]$

Untuk $20 \operatorname{deg}=<\mathrm{w}<90 \operatorname{deg}$

$P_{b}=1,52\left\{\frac{2 t}{D} \sigma_{\text {flow }}\left[\frac{1-\frac{2}{3}\left(\frac{d}{t}\right)}{1-\frac{2}{3}\left(\frac{d}{t M}\right)}\right]\right\}-0,02\left[\frac{(w-20) \text { deg }}{1 \text { deg }}\right]$

Untuk $\mathrm{w}=>90 \mathrm{deg}$

$P_{b}=1,37\left\{\frac{2 t}{D} \sigma_{\text {flow }}\left[\frac{1-\frac{2}{3}\left(\frac{d}{t}\right)}{1-\frac{2}{3}\left(\frac{d}{t M}\right)}\right]\right\}-0,003\left[\frac{(w-90) \text { deg }}{1 \text { deg }}\right]$

Hasil penelitian diatas juga sudah disimulasikan dan menghasilkan hal yang sama untuk cacat korosi dengan lebar korosi terputus (tidak kontinu).

Pada Tabel 2 diatas terdapat kasus $6^{*}$ yang sengaja ditambahkan untuk dipakai dalam perbandingan hasil persamaan dalam penelitian ini dengan persamaan (4) dari hasil penelitian 
yang menyertakan parameter lebar korosi untuk menghitung tekanan pecah yang dilakukan oleh Mustaffa dan van Gelder [8] untuk cacat korosi yang dangkal (d/t<=0,3), pendek (L/D $<=0,20)$, dan lebar (w/t>0,5). Agar sesuai dengan kondisi batas pada persamaan (4) dan karena lebar korosi kasus $6^{*}$ adalah $33 \mathrm{~mm}$ atau dalam derajat keliling pipa ini adalah 12,4 deg, persamaan dari hasil penelitian ini yang dipakai untuk perbandingan adalah persamaan untuk panjang korosi yang pendek dengan korosi yang lebar $\mathrm{w}<20$ deg yaitu persamaan (5). Berikut hasil perhitungan dan perbandingannya.

Perhitungan dengan persamaan (4):

$$
\begin{aligned}
& \frac{P_{b}}{455,05}=\left(\frac{9,53}{323,85}\right)^{0,8442}\left(\frac{2}{9,53}\right)^{-0,0545}\left(\frac{34}{33}\right)^{-0,014}, P_{b}=25,24 \mathrm{MPa} \\
& \text { Perhitungan dengan persamaan }(5): \\
& \text { Dicari dulu nilai M dari persamaan }(2) \\
& M=\sqrt{1+0,8\left(\frac{34}{323,85 \times 9,53}\right)^{2}}=1,14 \\
& \quad \text { Maka } P_{b} \text { dari persamaan }(5), \\
& P_{b}=1,13\left\{\frac{2 x 9,53}{323,85} \times 1,1 \times 358,53 x\left[\frac{1-\frac{2}{3}\left(\frac{2}{9,53}\right)}{1-\frac{2}{3}\left(\frac{2}{9,53 \times 1,14}\right)}\right]\right\}-0,026\left[\frac{(20-12.4)}{1 \text { deg }}\right]=\mathbf{2 5 , 5 2} \mathbf{M P a}
\end{aligned}
$$

Dapat dilihat bahwa tekanan pecah yang dihitung dengan persamaan (5) hasil penelitian ini memberikan hasil yang relatif sama, dengan selisih kurang lebih 1\% saja dari tekanan pecah yang dihitung dengan persamaan (4) pada penelitian Mustaffa dan van Gelder [8]. Dari hasil ini, dapat dikatakan bahwa persamaan ASME-B31G yang sudah diberikan faktor koreksi yang mempertimbangkan lebar korosi pada penelitian ini memberikan hasil yang akurat.

\section{KESIMPULAN}

Kesimpulan yang dapat diambil dari Evaluasi Pengaruh Cacat Korosi Internal Pada Kegagalan Pipa Bawah Laut Dengan Metode Elemen Hingga dengan studi kasus: Pipa Transmisi Minyak Sepinggan ini adalah sebagai berikut:

1. Variasi lebar korosi pada penelitian untuk korosi internal pada pipa API 5L X52 ini berpengaruh terhadap tekanan pecah pada pipa. Semakin lebar, semakin kecil tekanan pecah pada pipa akibat cacat korosi. Dari hasil penelitian, untuk panjang korosi yang pendek, dimana $\mathrm{L}^{2} / \mathrm{Dt}<=20$, konservatisme penggunaan analisa level 1 ASME-B31G ada di kisaran $80-87 \%$ dari perkiraan tekanan pecah sebenarnya yang ditunjukkan oleh hasil FEM. Untuk panjang korosi yang panjang, dimana $\mathrm{L}^{2} / \mathrm{Dt}>20$, konservatisme penggunaan analisa level 1 ASME-B31G ada di kisaran 40-66\% dari perkiraan tekanan pecah sebenarnya yang ditunjukkan oleh hasil FEM.

2. Agar tekanan pecah yang dihitung menggunakan ASME-B31G dapat mendekati tekanan pecah sebenarnya, untuk itu, penggunaan analisa level 1 ASME-B31G perlu ditambahkan faktor koreksi terkait dengan lebar korosinya seperti pada persamaan 510.

Karena data eksperimen pengujian tekanan pecah dihasilkan dari bentuk cacat korosi yang sudah disederhanakan, pada penelitian ini, hanya dilakukan pencarian pengaruh lebar korosi terhadap tekanan pecah yang dibandingkan dengan pengitungan tekanan pecah dengan menggunakan kode analitikal ASME B31G level 1. Pada penelitian ini tidak dilakukan pengaruh bentuk cacat korosi dengan bentuk korosi riil dimana bentuk korosi dapat berbentuk seperti pulau terhadap tekanan pecah pipa dan perbandingannya dengan ASME B31G Level 1. 
Pemodelan dengan bentuk korosi yang riil tentunya sangat menarik untuk penelitian selanjutnya sehingga didapatkan juga faktor koreksi bentuk terhadap penggunaan ASME B31G Level 1 yang lebih akurat.

\section{DAFTAR PUSTAKA}

Alang, N.A., Razak, N.A., Shafie, K.A. and Sulaiman, A., 2013, Finite Element Analysis on Burst Pressure of Steel Pipes with Corrosion Defects, in 13th International Conference on Fracture, Beijing, China

ASME, 2012, ASMEB31G: Manual for determining the remaining strength of corroded pipelines, Technical report, American Society of Mechanical Engineers

Capelle, J., Gilgert, J., Dmytrakh, I., Pluvinage, G., 2011, The effect of hydrogen concentration on fracture of pipeline steels in presence of a notch, Engineering Fracture Mechanics, Volume 78 , Issue $2^{\text {nd }}$ of January, pp 364-373

Chevron, 2009, Pipeline Sepinggan Intelligent Pigging Report

Chiodo, M.S. and Ruggieri, C., 2009, Failure assessments of corroded pipelines with axial defects using stress-based criteria: Numerical studies and verification analysis, International Journal of Pressure Vessels and Piping, vol. 86, 164-176

DNV, 2010, DNV Recommended Practice RP-F101 Corroded pipelines, DNV Recommended Practice, Det Norske Veritas.

Kiefner, J.F. and Duffy, A.R., 1971, Summary of Research to Determine the Strength of Corroded Areas in Line Pipe, Technical report, Battelle Columbus Laboratories

Kiefner, J.F. and Vieth, P.H., 1993, Database of Corroded Pipe Tests PR-218-9206, PRCI Catalog No. L51689, Technical Toolboxes Inc., Texas

Maxey, W.A., Kiefner, J.F., Eiber, R.J., and Duffy, A.R., 1971, Ductile Fracture Initiation, Propagation and Arrest in Cylindrical Vessels Fracture Toughness, Technical report, ASTM STP514

Mustaffa, Z. and van Gelder, P., A, 2010, Review and Probabilistic Analysis of Limit State Functions of Corroded Pipelines, In Proceedings of the 20th International Offshore and Polar Engineering Conference, pages 626-632, Beijing, China

Orasheva, J., 2017, The Effect Of Corrosion Defects On The Failure Of Oil And Gas Transmission Pipelines: A Finite Element Modeling Study, A thesis submitted to the School of Engineering, University Of North Florida 